\title{
The multiple assessment of interpretation effectiveness: Promoting visitors' environmental attitudes and behavior
}

\author{
Aise KyoungJin Kim, David Airey and Edith Szivas
}

\begin{abstract}
Interpretation has been recognized as a useful tool in managing visitor behavior in nature-based tourism areas. This study explores a multiple assessment approach to identify the strengths and weaknesses of site-based interpretation in influencing multi-dimensional aspects of attitudes and behavioral intentions towards local environmental issues. Visitors to the Lulworth coastal area in England were studied using on-site questionnaire survey data. The results of the research highlight that the effectiveness of interpretation varied in relation to a number of different aspects of responsible environmental behavior and local conservation issues. The findings also reveal that it fostered visitors' awareness of and their support for management policies but its impacts were limited to site-specific responsible behavior related in this case to geological and environmental conservation.
\end{abstract}

\section{Keywords:}

Interpretation; Environmental attitudes; Responsible behavior; Environmental Conservation; Nature-based tourism

\section{INTRODUCTION}

In nature-based tourism areas, tourism planners have often turned to interpretation as a key visitor management tool in managing the balance between tourism development and environmental protection (Kuo, 2002; Newsome, Moor, and Dowling, 2002). The management objectives of interpretation have been reshaped from their educational origins, which Tilden described as aiming 'to reveal meanings and relationships through the use of original objects by first-hand experience, and by illustrative media' $(1977$, p.8). Several definitions now recognize that interpretation has secondary aims, as a means of contributing to the protection of the natural environment through revealing the meanings of an object, a culture or a place or enriching visitors' understanding of the place (Knudson, Cable and Beck, 1995; Moscardo, 1998; Tilden, 1977) while enhancing visitor enjoyment and satisfaction (Moscardo, 1998).

Previous research has revealed that interpretation can help to manage the negative impacts of tourism such as on-site environmental damage, changes to the wildlife behavior, pollution and vandalism caused by visitors, through providing visitors with information about alternative sites, routes, or activities. Interpretive programs can also enhance visitors' understanding of conservation issues and develop a positive environmental attitude. In turn, interpretation can help people to modify their behavior (Kuo, 2002; Moscardo, 1998/1999; Marion and Reid, 2007).

In order to maximise the benefits of interpretation, Knudson et al. (1995) emphasized that the evaluation process should be considered as an integral part of the visitor management process as it provides useful feedback on whether desired management goals are being met. However, the effectiveness of interpretation on visitor attitudes and behavior change is not yet fully understood (Kuo, 2002; Newsome et al., 2002). Previous evaluation research has produced inconsistent 
findings (Beaumont, 1999/2001; Orams, 1997; Roggenbuck, 1992). Reasons for these mixed results include the relative impacts of a number of correlating factors (i.e. previous knowledge and attitudes), the effect of situational factors as well as the influence of the interpretive programs themselves and the individual's attributes (Beaumont, 2001). In tourism settings, it is noted that the negative impacts of the visitor on the natural environment occur over time rather than on one visit to the site. Thus, it is difficult to measure the immediate benefits of interpretation provision. It is also acknowledged that the effectiveness of interpretation varies depending on the type of behavior and the ways in which attitudes and behavior are conceptualized and measured (Ajzen, 1992; Ballantyne and Packer, 2005; Beaumont, 2001; Ham and Krumpe, 1996; Orams, 1997; Roggenbuck, 1992).

While a number of challenging issues are addressed in previous research, there is scope for further work on understanding 'when' interpretation influences behavioral change rather than questioning 'if' interpretation can make change or not. This involves determining what should be evaluated and how it should be measured (Knudson et al., 1995; Thom, 1980).

The purpose of this study is to explore a multiple assessment approach to examining different types of behavioral change through the interpretation experience. The study also examines under what circumstances and how different visitor groups change particular attitudes and behavior. This helps to establish why site-specific interpretation fails to have an influence in certain situations. The fieldwork focuses on the effects of the visitor center in a case study site in the South-West coastal region of the UK.

\section{LITERATURE REVIEW}

\section{Theoretical basis for effective interpretive strategies}

Several theories and conceptual models developed in the fields of environmental psychology and tourism provide a basis for the development of effective interpretive strategies. Petty and Cacioppo's (1986) Elaboration Likelihood Model (ELM) which has two distinct routes to persuasion (i.e. 'the central route to persuasion' and 'the peripheral route to persuasion') provides a useful understanding of the complex relationships among various factors that lead to different outcomes of interpretive programs (e.g. persistent behavior change, short-term behavior change or no change). Specifically, it goes some way to explain why interpretation sometimes fails to influence attitudes and behavior (Roggenbuck, 1992). This theoretical approach is used to guide the selection of the main variables to be considered for this current study.

The interpretive strategy based on the peripheral route to persuasion involves modifying overt behavioral change at least in the short term (Manning, 2003). This approach occurs when recipients are either unmotivated or incapable of processing the logical argument in the message (Petty, McMichael, and Brannon, 1992). Thus, the source factors (e.g. credibility, attractiveness, and personal style), incentives (e.g. punishment or rewards), language and style of message are important to attract and maintain the passive/non-captive audience's attention (Manning, 2003). In this regard, this approach may be acceptable when the focus of management goals is on prompting spontaneous behavior and reducing or solving specific problems only temporarily, because it fails to consider issue-relevant reasons for behavior (Manning, 2003; Roggenbuck, 1992).

The strategy based on the central route to persuasion focuses on underlying behavioral variables such as knowledge or beliefs, attitudes, and behavioral intentions (Petty and Cacioppo, 1986). In contrast to the peripheral route, this central route to persuasion occurs when the individual is motivated and capable of processing the issue-relevant arguments in the message 
through careful thought or the elaboration and integration of the message. Such elaboration and integration results in the creation of new beliefs or changes in old beliefs, and this in turn leads to desired changes in behavior (Petty et al., 1992; Roggenbuck, 1992). This approach reflects the traditional perspective of the knowledge-attitude-behavior link, and attitude-related theories (e.g. the theories of reasoned action and planned behavior) developed by Ajzen and Fishbein (1980) and Ajzen (1991) which address different types of beliefs shaping voluntary behavior. The many characteristics of the message content, of the channel of communication, and of the situation can be also determinants of the success of persuasion via the central route. The central route to persuasion is likely to be the preferred strategy to produce enduring changes in attitudes with behavioral consequences and a sensitive and low-impact ethic among park visitors (Petty et al., 1992).

The Elaboration Likelihood Model (ELM) recognizes that recipient characteristics have a powerful influence over the relative success of the various routes to persuasion (Roggenbuck, 1992). That is, although visitors receive persuasive information in tourism settings, information will not have a positive impact on all types of behavior of all ranges of visitors. These individual attributes (e.g. visitors' interest, existing attitudes, prior knowledge and past experiences) will mediate different outcomes (Ajzen, 1992; Roggenbuck, 1992). It is suggested that attention must be paid to the important role of individual differences and message effectiveness in different situations in order to develop and design effective influences of interpretation on the desired outcomes.

\section{The evaluation of interpretation effectiveness on environmental behavior}

The management goals of interpretation in the context of natural areas focus on change to lowimpact behavior and ultimately long-term conservation behavior. Previous research has revealed that the effectiveness of persuasive interpretation varies according to the type of environmental behavior (Manning, 2003; Marion and Reid, 2007; Roggenbuck 1992).

For example, problem or unintentional behavior and uninformed actions (e.g. off-trail hiking, picnic table carving, wildlife feeding and littering) may be considerably altered by information and interpretive programs. Several researchers have shown successful impact on such behavior (Littlefair, 2003; Oliver, Roggenbuck and Watson, 1985; Orams and Hill, 1998; Orams, 1997; for further review, see Marion and Reid, 2007). Roggenbuck and Passineau (1986) evaluated the effectiveness of interpreter-guided field trips at the Indiana Dunes National Lakeshore, USA. They found that anti-littering messages and role modeling by the interpreter affected children's littering behavior through changing their attitudes toward protection and conservation as well as changing their behavioral intentions. A study of visitors to Mon Repos Conservation Park, Australia by Howard (2000) had similar results. Here, interpretation promoted visitor's selfreported behavior through influencing increased knowledge regarding turtle conservation and, ultimately, influenced their actual behavior in the six months since their visit.

By contrast, other researchers have pointed to the difficulties of influencing illegal actions (violations of the site rules or regulations) or long-term conservation behavior through interpretation (Beaumont, 2001; Manning, 2003; Orams, 1997; Roggenbuck, 1992). For example, a few empirical studies (e.g. Dresner and Gill, 1994; Orams, 1997) found that interpretation had significant impacts on environmental behavior (e.g. buying ecologically friendly products, making a donation to an environmental organization, recycling, using public transport, etc.) while others found there was no impact (Beaumont, 2001).

While the influences of interpretation effectiveness can be different in terms of types of and 
aspects of behavior and situations, much previous research of measurement objectives have evaluated mainly site-specific inappropriate behavior at a certain site rather than long-term conservation behavior generally. Additionally, not much has been studied to measure multi-act behavior in terms of both site-specific and general perspectives, even though the management role of interpretation involves influencing various types of visitor behavior in a particular tourism setting rather than targeting a single type of behavior or management issue (Roggenbuck, 1992; Widner and Roggenbuck, 2000).

\section{The evaluation of interpretation effectiveness on environmental attitudes}

Attitude is regarded as one of the strong determinants affecting behavior and the basis for a beneficial outcome of interpretation experiences (Ballantyne and Packer, 2005). However, definitions and measurements of environmental attitudes are problematic. They have been conceptualized in various ways and they are expressed in different terms (i.e. 'concerns', 'values', and 'worldview') apart from 'attitudes'. Indeed, these have been used interchangeably in the literature (Schultz et al., 2004). Schultz et al. (2004) define the term 'environmental concern' as the affect (i.e. worry) associated with beliefs about environmental problems. 'Environmental attitude' is defined as 'the collection of beliefs, affect, and behavioral intentions a person holds regarding environmentally related activities or issues' (Schultz et al., 2004, p.31). The major distinct conceptualizations of 'environmental concern' or 'environmental attitudes' seem to range from a broad general attitude toward the environment to a specific attitude toward environmentally related actions or issues (Fransson and Gärling, 1999).

On this point, in the context of tourism research, various scales and statements have been employed to measure the conceptualization of environmental attitudes. Some have not been tested for reliability, validity and internal consistency (Beaumont, 1999). Many of recent studies using a sample of visitors to nature-based tourism destinations have examined site-specific environmental issues based on multidimensional aspects of attitudes (e.g. Littlefair, 2003; Madin and Fenton, 2004; Orams, 1997; Tubb, 2003). Some studies have used the theory of reasoned action (TRA) proposed by Ajzen and Fishbein (1980) in measuring specific environmental attitudes towards a particular behavior (e.g. Aipanjiguly, Jacobson, and Flamm, 2003; Bright et al., 1993; Brown, 1999; Chandool, 1997).

The results of these empirical studies based on different theories and target variables have produced inconsistent findings. Some studies have found that interpretation has a significant impact on increasing knowledge, and occasionally promoting favorable attitudes, which in turn has led to visitors' willingness to engage in low-impact behavior. This suggests a positive link between knowledge, beliefs, attitudes and intentions (Bright et al., 1993; Howard, 2000; Roggenbuck and Passineau, 1986). In some cases, interpretation researchers and resource managers have evaluated the influence of knowledge-based information in changing behavior and reported its failure (Ham and Krumpe, 1996; Orams, 1996). Other researchers have found only modest levels of effect on awareness and behavior and an unclear link between knowledge, attitude, intentions, and behavior (Beaumont, 2001; Espiner, 1999; Orams, 1997; Tubb, 2003). Given the various approaches and settings it is very difficult to compare the results of the various studies.

Empirical evaluation studies of attitudinal variables have produced several challenging issues, but provide little practical guidance on what to evaluate and how to implement evaluations of interpretive programs (Madin and Fenton, 2004). To date, numerous attitudinal studies have identified the complex relationships between multiple aspects of attitudes and other psychological 
variables and the prediction of attitude-intention-behavior (Kaiser, Wölfing, and Fuhrer, 1999). While arguments continue about the best way of measuring the core antecedent variables which are salient to the target behavior, Fransson and Gärling, (1999) suggest that both narrowly defined and more generally defined environmental attitudes need to be measured as both are important determinants of various types of pro-environmental behavior.

This argument, applied to an interpretive programme suggests that behavioral change can accordingly be influenced by effective interpretation tailoring to primary beliefs that are important to the target audience (Ballantyne and Hughes, 2006; Monroe, 2003). In this regard, several researchers propose an alternative interpretive strategy for the design of effective belief- or feelingtargeted messages, drawn from attitude-based theories, providing a guideline about the core influential attitudinal variables to influence pro-environmental behavior (Ballantyne and Packer, 2005; Ballantyne and Hughes, 2006; Ham and Krump, 1996; Orams, 1996). These include personal knowledge of action strategies and issues, beliefs about outcomes of a given behavior, feelings toward a particular behavior or issue, appreciation and concern for the environment, development of intentions to engage in pro-environmental behavior (Ballantyne and Packer, 2005; Cottrell, 2003; Orams, 1996).

To be effective, interpretation managers need to evaluate the effects of interpretation on the multiple measures and examine which visitors' beliefs (or feelings) really influence how they behave in a particular situation as a result of their interpretive experience (Ham and Krumpe, 1996; Ballantyne and Hughes, 2006). But there have been few empirical studies in this context. Thus, the key targeted variables were used to guide the development of the current study.

\section{RESEARCH OBJECTIVES}

Considering the limited research outcomes addressed in the literature, this study examines a multiple measurement approach to identify the strengths and weaknesses of site-based interpretation in influencing multi-dimensional aspects of attitudes and behavioral intentions in relation to a variety of management issues and practices.

As tourism settings attract heterogeneous groups of visitors (e.g. non-captive audiences, adults, local residents, nature-based tourists, family-oriented tourists), selected key visitor characteristics drawn from the key components of the ELM theory were incorporated into the current research design in order to understand the different levels of interpretation effectiveness according to visitors' interest and involvement in interpretation.

By identifying specific subgroups of visitors, the aim is to enhance understanding of individuals' different interpretive experiences. In doing so it is hoped that the findings of this study will allow managers to develop and design more focused interpretation strategies to target each group's beliefs, needs and interests, while providing appropriate educational opportunities to modify their attitudes and behavior.

\section{Lulworth coastal area}

\section{STUDY SITE}

The Lulworth coastal area is located in the south-west of England, in the county of Dorset. The unique environment of Lulworth Coast contains several tourism attractions including Lulworth Cove, Durdle Door and Fossil Forest, as well as wildlife, human activities and archeological heritage. In particular, Lulworth Cove itself is a beautiful shell-shaped cove which was formed by coastal erosion (The Lulworth Estate, 2002).

Given its international reputation for stunning coastal scenery and geology, the Lulworth 
coastal area has long been popular for both domestic and international visitors attracting annually over half a million visitors, particularly concentrated during the summer (Dorset For You Partnership, 2005; The Lulworth Estate, 2002). While the economic benefits of tourism to this area are significant, the increasing tourism pressure brings management concerns, particularly, in relation to the erosion of footpaths and coastlines and the domination of the car park in the area surrounding Lulworth Cove (The Lulworth Estate, 2002).

In order to achieve a balance between environmental, economic and social sustainability, several management policies have been set up by the Lulworth Estate, which has owned much of Lulworth since 1641 (The Lulworth Estate, 2002). For example, while increasing public access to the coast is the main management objective, visitors are encouraged to use footpaths and steps to access several attractions (e.g. cliff-tops, beaches and the Fossil Forest) in order to reduce the severe cliff erosion and to ensure walkers' safety. Some visitor activities have been restricted including climbing the cliffs fossil collecting and limited beach access. Climbing the coastal cliffs, which means roped activities, or hammering the cliff face are particular problems due to the damage to the chalk, the disturbance to wildlife and frequent rock falls. The natural cliff erosion uncovers a huge number of fossils, particularly, at the middle of the cliff. However, as professional and semi-professional climbers visit Lulworth to collect fossils from the chalk for scientific research, they tend to encourage visitors without experience or equipment to climb dangerous and unstable coastal cliff formations (The Lulworth Estate, 2002). It is recommended that visitors only collect fossils from beach. The Lulworth Estate encourages visitors to take a small hammer and hard hats when collecting fossils from the foreshore because of frequent rock falls (UK Fossils Network, 2005; The Lulworth Estate, 2002).

In terms of the practical application of these policies to the visitor management strategy, interpretation has been employed as one of the main visitor management tools by Dorset County Council at this site (Johnson, 2002). The interpretive media include signs, brochures, guides, publications, an internet website, and the Heritage Center. Brochures and signs contain a Visitor Code for their own safety and for conservation, setting out appropriate responsible behavior for fossil collection and walking on the beach. The Lulworth Cove Heritage Center serves many different functions, including marketing and access, enhancement and information, management and substitution for the attractions themselves (Moscardo, 1998/1999). This is one of five Coastlink visitor centers on the Dorset Coast that was developed by voluntary groups and local stakeholders in order to raise awareness of the relatively unknown and unexplored marine and geological environment (Dorset Coastlink, 2010a). The centre provides exhibitions and displays showing the geological features, rocks, fossils, coastal erosion process and wildlife as well as a video of the sea showing the impacts of a winter storm on the natural erosion of the coast (The Lulworth Estate, 2002). The Lulworth Cove Heritage Center is open daily with free admission and provides various publications (books, leaflets, brochures, and maps) and tourism facilities such as a souvenir shop, toilets, restaurants and car parks. Educational tours for school children, students and the public are also available.

\section{Survey}

\section{METHOD}

A self-administered questionnaire was created to evaluate the effects of interpretation on visitors' attitudes and behavioral intentions. The survey was undertaken at Lulworth Cove over five days in July 2005 including both weekdays and weekends. Five trained research assistants approached visitors in beach areas and at the entrance to Lulworth Cove Heritage Center. Non- 
English speaking visitors and those under 18 years of age were excluded. In line with previous data about visitors to Dorset during the period May to September the current research indicated that the majority of visitors were independent domestic tourists. They were mainly in the 35 to 64 age groups with noticeably fewer visitors aged between 18 and 24 (Dorset For You Partnership, 2005).

Given the exploratory nature of the study, the respondents were selected based on a convenience sampling method. They were provided with a brief introduction and explanation about the purpose of the study before being asked for their agreement to proceed. The questionnaire took approximately 15 to 20 minutes to complete. A total of 421 useable questionnaires were received out of 575. Of these 216 respondents had not yet been to the Visitor Center on that visit, while 205 had already been to the Center.

\section{Measurement of variables}

The questionnaire consisted of a series of questions regarding demographic characteristics, trip motivations for visiting the study site, experiences of the Visitor Centre, and use of interpretation programs. Respondents were also asked to answer questions dealing with 31 attitudinal items and 13 behavioral items in relation to local management issues and environmental behavior (see Tables 1 and 2). Site-specific issues and types of low impact behavior were identified using a variety of qualitative techniques. These included analysis of publications and other interpretive programs available in this case study site as well as informal exploratory interviews with the manager of the Visitor Center. Ultimately the survey focused on three local environmental issues (i.e. protection of cliffs, fossils and the coast) and responsible behavior associated with each of these.

\section{Attitude measurement}

An attitude measure was developed from a combination of existing statements (Aipanjiguly et al., 2003; Brown, 1999; Lee and Balchin, 1995; Tubb, 2003) and the multidimensional concepts of environmental attitude constructs identified by previous researchers (Ajzen and Fishbein, 1980; Ballantyne and Packer, 2005; Orams, 1996). The measure was made up of sub-dimensions as follows: (i) the importance of protection of the three local environmental issues (i.e. protection of cliffs, fossils and the coast) and responsible behavior; (ii) awareness of the negative or positive consequences of each type of behavior (i.e. climbing, collecting fossils from the cliffs and picking up beach litter); (iii) visitor support for the management policies regarding each type of behavior; and (iv) feelings of concern about the three local environmental issues or types of behavior. In total it consisted of 31 attitudinal items measured on Likert type scales, including 22 belief-type statements (ranging from $1=$ strongly disagree to $5=$ strongly agree) and 9 emotion-based statements (ranging from $1=$ not seriously concerned at all to $5=$ very seriously concerned). For the measurement of the emotional items a unipolar scale was employed instead of a bipolar semantic differential scale as this latter could force respondents to make 'a choice of favorability or unfavorability' (Bagozzi, Gürhan-Canli and Priester, 2002, p.94). The unipolar scale can be useful in representing the intensity of respondents' different emotional reactions (Bagozzi et al., 2002).

Some minor changes to the items were made following several pilot studies prior to the main survey. In particular, selecting various types of salient belief and feeling components of attitudes was a difficult task because of site-specific issues and the lack of methodological background or previous empirical research at this case study site. The pilot survey conducted at Lulworth Cove 
in June 2005 indicated a low level of internal consistency reliability for the attitude measure, although it was acceptable in an exploratory study with a Cronbach alpha of at least over 0.6. In order to improve the reliability, acceptable survey techniques were used by expressing some belieftype statements negatively in order to minimize response bias (Oppenheim, 1996) or dropping some items. The following pilot survey conducted at the beginning of July, 2005 and the main survey showed a much higher internal consistency (all 31 attitude statements) with a Cronbach Alpha of 0.888 .

\section{Behavioral intention measurement}

The extent of visitors' commitment to participate in specific and general activities was measured using a 5-point Likert scale ( $1=$ strongly disagree to $5=$ strongly agree). Multiple-act criteria for responsible environmental behavior were employed and developed from statements used in previous studies (Beaumont, 2001; Monroe, 2003; Orams, 1997). These consisted of 13 items that are derived from three sub-dimensions as follows: (i) site-specific responsible behavior; (ii) general responsible behavior; (iii) environmental activism behavior. The results of several pilot studies and the main survey showed a high level of reliability on this measure with a Cronbach Alpha of 0.847. For this reason negatively expressed statements were not included in the behavioral intention scale.

A factor analysis with Varimax rotation was performed to assess the construct validity and to explore the underlying sub-dimensions of each of two indicators. The results of the factor analyses of all scales were acceptable (Kaiser-Meyer-Olkin measure of sampling adequacy was over .80). Environmental attitudes yielded eight factors that corresponded with the three site-specific conservation topics and theoretically defined specific attitude concepts (i.e. belief or feeling components for each of the conservation topics). For a multi-set of responsible behaviors, two factors were identified reflecting specific responsible behavior and general environmental activism.

\section{DATA ANALYSIS}

To examine the effect of interpretation on visitors' attitudes and behavioral intentions, respondents were categorized on the basis of their reported experience of the Visitor Center. Table 3 shows how the sample is distributed according to the two main criteria which were visitors' intention to visit the Center and their previous experience of the Center, as reviewed in the persuasion theory (ELM). Three main questions were used for categorizing subgroups of visitors: (1) present experience of the Center (2) intention to visit the Center and (3) past experience of the Center. About one half $(n=205)$ of all respondents $(n=421)$ indicated that they had visited the Center on this occasion. Of those who had not visited the Center on this occasion $(n=216)$ only 58 $(27.1 \%)$ indicated that they planned to visit. As for previous experience of the Center, $161(38.6 \%$ of valid responses) had visited before.

Based on these questions, the total sample was initially divided into four sub-groups (1) 'those who had not visited the Center before and had no intention of doing so', (2) 'those who had not visited the Center before but planned to visit on this occasion', (3) 'those who had not visited the Center yet on this occasion but had previous experience', (4) 'those who had visited the Center this occasion'. A series of ANOVA tests showed that there were significant differences in visitor attitudes and behavioral intentions scores between the four sub-groups. However, further analysis (the post hoc test-Tukey method) revealed no statistical differences in the two dependent variables (i.e. attitudes and behavioral intention scores) between (3) 'those who had not visited today but 
had previous experience of the Center' and (4) 'those who had visited the Center this time'. Hence these two groups were combined. For the final analysis, three sub-groups were formed: Group I ('non-visitors'): 'those who had not visited the Center at all and had no intention of doing so'; Group II ('interested visitors'): 'those who planned to visit the Center but had not visited before'; Group III ('experienced visitors'): 'those who had visited the Center before and/or on this occasion'. These three sub-groups were used to determine the effects of the Visitor Center on visitors' attitudes and behavioral intentions in further analysis.

The Statistical Package for the Social Sciences Version 12.0 for Windows was used to analyze the data. A series of Chi-Square and ANOVA tests were conducted to compare the differences in several indicators among the three sub-groups.

\section{Visitor profiles}

\section{RESULTS}

The three sub-groups had similar profiles and a series of Chi-square tests indicated no significant differences for most characteristics. The exceptions related to age, education, previous experience of natural areas and motivation for the trip. Results are given in Tables 4 and 5. The 'experienced visitors' (Group III) were older, had more previous experience of natural areas and were more interested in "learning about protection" than the other two groups. The 'non-visitors' (Group I) and 'interested visitors' (Group II) respondents (over 50\%) had a higher proportion of university degrees than the 'experienced visitors' (Group III) respondents (38\%).

\section{The type of interpretation participation}

Table 6 shows different levels of visitor participation in the type of interpretive programs that they used at the site. The Visitor Center provided exhibition/displays, computer interactions, films, and publications focusing on the coastal and geological environment as well as the local history. Other types of interpretive programs included signboards, brochures, guided walks, talks to the staff, and others (e.g. maps). The results of Chi-Square tests showed that there were significant differences among the three sub-groups in types of interpretation participation. The 'experienced visitors' were more likely to use a number of different types of interpretive programs (e.g. different types of media within the Center and elsewhere) while the 'non-visitors' and 'interested visitors' typically only used one or two, mainly 'signboards' and 'brochures'.

\section{The effects of the Visitor Center on attitudes}

Most respondents' attitudes were strongly positive as regards the quality of coastal areas, responsible behavior, fossil protection and cliff protection. In particular, most respondents agreed strongly that 'it is important to protect the quality of the coastal area', and 'beach litter contributes to water pollution'. They generally disagreed with the economic benefits of fossil collecting.

With regard to comparisons among the three sub groups (Table 7), the results of a one-way ANOVA test showed that significant differences were found in 19 items including beliefs about specific issues regarding 'cliff erosion' and 'climbing', 'importance of protection', 'negative impacts of fossil collecting', and 'support for picking up beach litter'. Overall, those who had experienced the Visitor Center appeared to have a significantly and positively enhanced level of beliefs and concerns about 'cliff erosion' and 'climbing the cliffs', followed by 'negative impacts of fossil collecting'. However, no significant differences were apparent in beliefs and concerns about 'negative impacts of beach litter' or about 'positive outcomes of fossil collecting' (e.g. 'helping science research' and 'economic value of fossil collecting'). The 'experienced visitors' 
had a higher score on these conservation issues than the other two groups.

More detailed, post-hoc tests (Tukey and Scheffe methods) demonstrated that no significant differences were found between the 'non-visitors' (Group I) and 'interested visitors' (Group II). However, comparison between Group I and III, indicates that the 'non-visitors' had less positive attitudes about 'cliff erosion' and 'fossil protection' and were significantly different from the 'experienced visitors'. In comparison between the 'interested visitors' and 'experienced visitors', significant differences between the two groups were found in their beliefs that 'it is dangerous to climb the cliffs' and 'collect fossils from the cliffs', and concern about 'people not keeping the footpaths on the cliffs'.

\section{The effects of the Visitor Center on behavioral intentions}

Most visitors had a high level of positive intention toward general environmental behavior while they had a lower level of intentions toward 'donation', becoming 'a member of an environmental organization', and 'volunteer work'. In addition, respondents' intentions were less favorable on 'removing beach litter' 'telling people about the importance of the geological environment in this area' and 'involvement in environmental issues'.

Table 8 sets out the significant findings about the commitment of respondents to changing their behavior in comparisons among the three subgroups. The results of a one-way ANOVA test showed that there were differences among the three groups in 6 environmental behavior items (i.e. 'not collecting fossils', 'informing about the discovery of special fossils', 'not climbing on the cliffs', 'keeping to the footpaths', 'behaving in a way that will not harm plants and animals', and 'becoming involved in environmental issues'). There were no significant differences among the three groups in relation to environmental activism and other general environmental behavior.

The post-hoc tests (Tukey and Scheffe methods) indicated that the 'experienced visitors' had a higher mean score in all these 6 items in which there were significant differences between the 'non-visitors' and 'experienced visitors'. The comparison between the 'non-visitors' and 'interested visitors' showed significant differences in one item, 'not collecting the fossils'. Significant differences between the 'interested visitors' and 'experienced visitors' also existed in relation to 'informing about the discovery of fossils' with the 'experienced visitors' more likely to act positively.

\section{DISCUSSION AND CONCLUSIONS}

This study reports on an attempt to examine the strengths and weaknesses of interpretation as a visitor management tool in promoting different types of environmental attitudes and behavior with regard to multiple site-specific management issues. In doing so it seeks to suggest that this approach is more effective than determining its influence on limited target variables in relation to a particular topic or a single type of behavior (Ballantyne and Hughes, 2006; Maddin and Fenton, 2004; Ham and Krumpe, 1996; Lee and Balchin, 1995).

It contributes to an understanding of how different sub-groups behave and the measurement of attitudes and behavioral intentions in specific and general contexts. The key findings echo the evidence of previous literature which indicates that interpretation efforts partly succeed in altering visitor behavior but its impacts are limited to site-specific issues. It was evident that most effects were found in relation to specific attitudes and behavioral intentions towards two local environmental issues, 'cliff protection' and 'fossil protection'. However, it had less effect in relation to general attitudes towards environmental protection or to more general behavioral intentions such as removing beach litter or involvement in environmental activism. This is 
consistent with the findings of Tubb (2003), that within the High Moorland Visitor Center at Dartmoor National Park, UK, the Center was effective only in changing attitudes related to the feeding of wildlife, but that no effects on general attitudes toward the natural environment were seen.

The multiple measurements of environmental attitudes and behavior provide valuable insights into an improved understanding of 'when' interpretation is effective in influencing different types of attitudes and behavior. Results highlight that visitors who had been exposed to the Visitor Center had a higher level of awareness of, concern about, and support for management policies toward the negative outcomes of the specific problem behavior compared to those who had not been to the Center. This key finding is consistent with the TRA's (Ajzen and Fishbein, 1980) proposition, that increasing specific beliefs about a particular behavior is strongly associated with specific attitudes and behavioral intentions towards given types of behavior. Supporting this notion, in the case of Lulworth Cove, it was evident that visitor management policy has resulted in a significant downturn in the number of climbing related accidents (e.g. using ropes or hammers to collect fossils from the cliff) (The Lulworth Estate, 2002) as the interpretive media (e.g. films, exhibits, brochures, website, and signboards) emphasizes the unstable coastal environment (e.g. natural cliff erosion) and behavioral concerns for visitor safety.

This supports the premise that influencing actions require specific belief-based or feelingbased information about the consequences of the actions, the associated consequences, and the basic human emotions of fear, anxiety and pity, when management issues are targeting sitespecific responsible behavior (Ballantyne and Packer, 2005; Monroe, 2003; Roggenbuck 1992).

The study also helps to identify the weaknesses of the current interpretation in promoting certain types of long-term conservation behavior, consistent with the findings of previous research (Beaumont, 2001). Limitations in its effects on long-term conservation behavior (e.g. 'giving donations', 'volunteer work', and 'membership of environmental organization') or responsibilitydenial behavior (i.e. 'removing beach litter') suggest that different strategies should be considered for these.

This finding indicates that the current interpretive messages targeting general attitudes may be poor determinants of these types of behavior. For example, the focus of the Center is on raising visitors' awareness about the coastal and geological environment and protection of these resources. Other types of interpretive programs (e.g. brochures) contain only factual information highlighting the Visitor Code such as "keep the shore tidy" and "take your litter home" that visitor should change but with limited explanations about the consequences of beach litter in detail (Dorset Coastlink, 2010b). Thus, managers need to go one step further and evaluate the effects of different interpretive strategies (e.g. conveying specific responsibility-targeted messages, the ease with which the action can be done, or reducing barriers to the particular behavior) (Adams, 2003; Monroe, 2003; Roggenbuck, 1992) which are stronger determinants of general conservation behavior in order to improve the effects of the current interpretive program (Ballantyne and Packer, 2005; Cottrell, 2003; Orams, 1996).

Other factors might be considered to explain why site-specific interpretation fails to have an influence on general environmental attitudes. This might be related to a 'ceiling effect' or 'social desirability' (Chawla, 1999). This study confirms arguments by previous researchers in identifying that both visitors to nature-based activities and the wider public have generally environmentally favorable attitudes and they do not change significantly through interpretation due to a 'ceiling effect' (Asfeldt, 1992; Beaumont 2001; Orams 1997). Thus, the previous welldefined attitudes appear to mediate the outcome of interpretation. As Orams (1997) argues, the 
possible reason for the findings might also be the influence of 'social desirability'. As most visitors are aware of conservation issues and environmentally responsible behavior, visitors may have simply responded in a manner that is consistent with well-known and socially accepted views about environmental issues and positions, and not on the basis of how they really feel (Ewert and Baker, 2001; Orams, 1997). As a result some of the attitude statements regarding the general environment and responsible behavior used in this study (e.g. 'it is important for visitors to behave in an environmentally responsible way', 'it is important to protect the quality of the coastal area') might need to be modified in further study.

Despite the limitations, this study helps interpretive planners or tourism managers to use these findings in making a careful decision about what approach works best for different types of visitors (high motivation to process the message and high knowledge vs low motivation to process the message and low knowledge). Unlike national parks or ecotourism-based settings, this study site offers a wide range of tourist activities which attract both sun and sea tourists with relaxation motivations as well as nature-based tourists. Accordingly, interests and preferences for interpretive programs vary.

As mentioned in the persuasion theory (ELM) (Pretty and Cacciopo, 1986; Petty et al., 1992), the central route to persuasion approach appears to be effective in modifying site-specific lowimpact behavior for the 'experienced visitors' (Group III) who were older, had high interest in the natural environment, and a desire to learn about the site-specific issues while visiting the site. On the other hand, this study suggests that special attention should be paid to the 'non-visitors' (Group I) who were younger, had lower levels of environmental awareness, and lack of interest in on-site interpretive messages. Younger people might only be interested in visiting the beach for swimming or sunbathing (perhaps with children) or they might be more interested in the challenges presented by the cliffs and fossil collection. Thus, the peripheral route to persuasion approach is necessary to target immediate on-site modification of a new attitude or spontaneous behavior.

In this regard, the results of this study emphasize that different interpretive strategies according to the types of behavior need to be applied through tailoring to the preferences and perceptions of targeted audience groups (Roggenbuck, 1992).

\section{THEORETICAL AND METHODOLOGICAL IMPLICATIONS}

In terms of research design issues, it is clear that this is one of the challenges in tourism settings to develop appropriate research designs given the attempt to evaluate a single and direct impact of interpretation as the use of experimental research designs requires adequate control of all potential confounding variables (Marion and Reid, 2007). Much previous research has often used the research design of the pre-visit and post-visit groups but there is also considerable difficulty in matching the profiles of the two sub-groups for such comparisons in the field setting (Lee and Balchin, 1995). In this study, an attempt has been made to overcome these difficulties, in relation to experience of the Visitor Centre, by making the groups sufficiently large to produce subgroups that are equivalent on some significant relevant variables (Lee and Balchin, 1995; Oppenheim, 1996). Thus, considering the active role of visitors in their response and involvement in the interpretive programs addressed in the persuasion model (ELM) (Pretty and Cacciopo, 1986), these key visitor-related factors (i.e. non-visitors, visitors' intention to experience, and previous experience of the Visitor Center) were incorporated into the group comparisons, hence arriving at the three subgroups that were used in the analysis. This approach was found to be effective in identifying different levels of persuasion effects among the three subgroups. 
However, it is always difficult to control for all confounding factors which are one of the problems in determining the direct impact of interpretation. This is possibly due to uncontrolled variables remaining even though the suspected confounding factors were matched across the groups (Oppenheim, 1996). Therefore, there will be doubt about whether or not revealed differences in attitude or behavioral intention are the result of exposure to interpretive messages in the Visitor Center or the differences of visitor characteristics. While it can be argued, further analysis needs to determine the relative impacts of these individual factors on attitude and behavior.

While the persuasion model is useful in understanding the multiple effects of interpretation, this model has a limitation in providing detailed guidance as to what and how to measure the attitude construct. This research supports the premise that each theory has its own limitations and cannot encompass all factors as the process of human behavior is very complex and difficult to change (Kollmuss and Agyeman, 2002; Widner and Roggenbuck, 2000). Some researchers agree that the theory of reasoned action (Ajzen and Fishbein, 1980) can be useful in determining the primary beliefs influencing a single and voluntary behavior but has limited application to investigate a variety of tourist behaviors (Lee and Balchin, 1995). Widner and Roggenbuck (2000) argue that the inconsistent and contradictory findings of the effectiveness of interpretation might be due to the way of examining behavior change research based on the particular theory. In this sense, this study did not attempt to test a particular theory for the measurement of attitudes. While applying one particular theory to the conceptual and operational measurement of attitudes and behavior could be valuable to some extent, the current study provides evidence that multiple measurements drawn from various attitude-related theoretical perspectives can be useful if the purpose of the study is to identify the effects of different levels of persuasion on various aspects of behavior or management issues. As Madin and Fenton (2004) argue, this approach can be seen as the effective evaluation method which allows practitioners to gain an insightful understanding of 'how well' or 'how much' management objectives of interpretation are being achieved and to establish what specific actions need to be taken to improve interpretation.

\section{LIMITATIONS AND FUTURE STUDIES}

The study has several limitations. The limitations in sampling need to be considered such as the sampling approach, the timing of the data collection and the locations selected which will introduce selection bias and a lack of generalizability of the results. This study sampled day visitors during summer, using a non-probability convenience sampling method. Informal interviews with the Center staff prior to the research indicated that different visitor groups visited over the year. For example, family groups visited mostly during summer vacations while young couples visited during the off-season. A survey incorporating a more diverse sample population would be useful.

The outcomes of the research may be influenced by several factors including the target audiences, messages, media channels, processing factors and situational factors as addressed in the persuasive communication literature (Hovland et al., 1953). The focus of this study was on the effects of visitor participation in the Visitor Centre as a simple indicator to evaluate the management objectives of interpretation. Distinctions of the relative effects of interpretive contextual factors were not made, however, due to the limited scope of the study. Thus, further study on other types of indicators such as the level of engagement, the direct and relative impacts of the type of media, the quality of programs offered, or the intensity and affective reactions to the persuasive message will validate effective techniques that might be useful to improve the design 
of interpretive programs.

The on-site interpretation in the case study site addresses the importance of protecting natural cliff erosion. Visitors might be confused by the lack of specificity in some attitude statements (e.g. 'the cliffs are eroding rapidly', 'it is important to keep cliff erosion to a minimum') as they are aware that cliff erosion is caused not only by the sea or the weather but also by inappropriate visitor behavior. Therefore, future research needs to explore their awareness of natural cliff erosion to validate the current research findings.

The current study did not examine actual behavioral change as a result of the interpretive experience. Further study should evaluate the effects of interpretation on conservation behavior onsite through observations and self-reported surveys or at home through a later follow-up survey. This may help to diminish the criticism in relation to its ineffectiveness on actual behavioral change in the longer term.

\section{REFERENCES}

Adams, W.J. (2003). Promoting environmentally responsible behavior: An evaluation of the global learning and observations to benefit the environment (GLOBE) program., Unpublished Master of Arts thesis, University of South Africa.

Aipanjiguly, S., S.K. Jacobson, and R. Flamm (2003). "Conserving manatees: Knowledge, attitudes, and intentions of boaters in Tampa Bay, Florida." Conservation Biology, 17(4): 1098-1105.

Ajzen, I. (1991). "The theory of planned behavior." Organizational Behavior and Human Decision Processes, 50: 179-211.

Azjen, I. (1992). Persuasive Communication Theory in Social Psychology: A Historical Perspective, In Influencing human behavior: Theory and Applications on Recreation, Tourism, and Natural Resources Management, edited by M.J. Manfredo. Champaign, Illinois: Sagamore Publishing Inc, pp.1-28.

Ajzen, I. and M. Fishbein (1980). Understanding attitudes and predicting social behavior. Englewood Cliffs, NJ: Prentice-Hall.

Asfeldt, M. (1992). The impact of guided wilderness canoe trips on the participants' attitudes to, concerns for and behaviors toward the environment. Unpublished masters thesis, University of Alberta, Edmonton.

Bagozzi, R.P., Z. Gürhan-Canli, and J.R. Priester (2002). The social psychology of consumer behavior. Buckingham: Open University Press.

Ballantyne, R. and K. Hughes (2006). "Using front-end and formative evaluation to design and test persuasive bird feeding warning signs." Tourism Management, 27(2): 235246.

Ballantyne, R. and J. Packer (2005). "Promoting environmentally sustainable attitudes and behavior through free-choice learning experiences: what is the state of the game?" Environmental Education Research, 11(3): 281-295.

Beaumont, N.K. (1999). Ecotourism: The contribution of educational nature experiences to environmental knowledge, attitudes, and behaviors. Unpublished $\mathrm{PhD}$ thesis. Australian School of Environmental Studies, Griffith University: Nathan, Queensland. (2001). "Ecotourism and the conservation ethic: Recruiting the uninitiated or preaching to the converted?" Journal of Sustainable Tourism, 9(4): 317-341.

Bright, A.D., M.J. Manfredo, M. Fishbein, and A. Bath (1993). "Application of the Theory of Reasoned Action to the National Park Service's Controlled Burn Policy." 
Journal of Leisure Research, 25(3): 263-280.

Brown, T.J. (1999). "Antecedents of culturally significant tourist behavior." Annals of Tourism Research, 26(3): 676-700.

Chandool, N. (1997). Participation in park interpretive programs and visitors' attitudes, norms, and behavior about petrified wood theft. Unpublished masters thesis. Department of Forestry, Virginia Polytechnic Institute and State University: Blacksburg.

Chawla, L. (1999). "Life paths into effective environmental action." Journal of Environmental Education, 31(1): 15-26.

Cottrell, S.P. (2003). "Influence of Sociodemographics and Environmental Attitudes on General Responsible Environmental Behavior Among Recreational Boaters." Environment and Behavior, 35(3): 347-375.

Dorset Coastlink (2010a). Coastlink. http://www.coastlink.org/centres.html (accessed 28 February 2010).

Dorset Coastlink (2010b). Seashore Code. http://www.costlink.org/PDFs/seashore\%20 Code.pdf (accessed 20 February 2010).

Dorset For You partnership. (2005). Dorset Tourism Facts 2002. http://www.dorsetforyou. com/index.jsp?articleid=332863 (accessed February, 2006).

Dresner, M., and M. Gill (1994). "Environmental education at summer nature camp." Journal of Environmental Education, 25(3): 35-41.

Espiner, S.R. (1999). The use and effect of hazard warning signs: Managing visitor safety at Franz Josef and Fox Glaciers. Science for Conservation Series no. 108. Wellington, New Zealand: Department of Conservation.

Ewert, A., and D. Baker (2001). "Standing for where you sit: An exploratory analysis of the relationship between academic major and environmental beliefs." Environment and Behavior, 33(5): 687-707.

Fransson, N., and T. Gärling (1999). "Environmental concern: conceptual definitions, measurement methods, and research findings." Journal of Environmental Psychology, 19: $369-382$.

Ham, S.H., and E.E. Krumpe (1996). "Identifying audiences and messages for nonformal environmental education: A theoretical framework for interpreters." Journal of Interpretation Research, 1(1): 11-23.

Hovland, C.I., I.L. Janis, and H.H. Kelley (1953). Communication and persuasion. New Haven: Yale University Press.

Howard, J. (2000). "Research in progress: Does environmental interpretation influence behavior through knowledge or affect?" Australian Journal of Environmental Education, 15/16: 153- 6.

Johnson, D. (2002). Towards sustainability: examples from the UK coast. In Sustainable tourism: A global perspective, edited by R. Harris, T. Griffin, and P. Williams. Oxford: Butterworth-Heinemann, pp.166-179.

Kaiser, F.G., S. Wölfing, and U. Fuhrer (1999). "Environmental attitude and ecological behavior." Journal of Environmental Psychology, 19: 1-19.

Knudson, D.M., T.T. Cable, and L. Beck (1995). Interpretation of Cultural and Natural Resources. State College, PA: Venture Publishing.

Kollmuss, A., and J. Agyeman (2002) "Mind the gap: why do people act environmentally and what are the barriers to pro-environmental behavior?" Environmental Education 
Research, 8(3), 239-260.

Kuo, I-L. (2002). "The Effectiveness of environmental interpretation at resource-sensitive tourism destinations." International Journal of Tourism Research, 4: 87-101.

Lee, T., and N. Balchin (1995). "Learning and Attitude Change at British Nuclear Fuel's Sellafield Visitors Centre." Journal of Environmental Psychology, 15: 283-298.

Littlefair, C.J. (2003). The effectiveness of interpretation in reducing the impacts of visitors in national parks. Unpublished $\mathrm{PhD}$ thesis, School of Environmental and Applied Sciences, Griffith University.

Madin, E.M.P., and D.M. Fenton (2004). "Environmental interpretation in the Great Barrier Reef Marine Park: An assessment of program effectiveness." Journal of Sustainable Tourism, 12(2): 121-137.

Manning, R.E. (2003). "Emerging principles for using information/education in wilderness management." International Journal of Wilderness, 9(1): 20-27.

Marion, J., and S. Reid (2007). "Minimizing visitor impacts to protected areas: The efficacy of low impact education programs." Journal of Sustainable Tourism, 15(1): 5-27.

Monroe, M.C. (2003). "Two avenues for encouraging conservation behaviors." Human Ecology Review, 10(2): 113-125.

Moscardo, G. (1998). "Interpretation and Sustainable Tourism: Functions, examples and Principles.” Journal of Tourism Studies, 9(1): 2-13. (1999). Making Visitors Mindful: Principles for Creating Quality Sustainable Visitor Experiences through Effective Communication, Champaign, IL: Sagamore.

Newsome, D., S.A. Moore, and R.K. Dowling (2002).. Natural Area Tourism: Ecology, Impacts and Management. Clevedon: Channel View Publications.

Oliver, S.S., J.W. Roggenbuck and A.E. Watson (1985). "Education to reduce impacts in forest campgrounds.” Journal of Forestry, 83(4): 234-236.

Oppenheim, A.N. (1996). Questionnaire Design, Interviewing and Attitude Measurement. London: Continuum.

Orams, M.B. (1996). "Using interpretation to manage nature-based tourism." Journal of Sustainable Tourism, 4(2): 81-95.

(1997). "The effectiveness of environmental education: Can we turn tourists into greenies?" Progress in Tourism and Hospitality Research, 3(4): 295-306.

Orams, M.B., and G.J.E. Hill (1998). "Controlling the ecotourist in a wild dolphin feeding program: Is education the answer?" Journal of Environmental Education, 29(3): 3339.

Petty, R.E., and J.T. Cacioppo (1986). "The Elaboration Likelihood Model of persuasion." In Advances in experimental social psychology (Vol. 19), edited by L. Berkowitz. New York: Academic Press, pp. 123-205.

Petty, R.E., S. McMichael, and L. Brannon (1992). The elaboration likelihood model of persuasion: Applications in recreation and tourism, In Influencing human behavior: Theory and Applications on Recreation, Tourism, and Natural Resources Management, edited by M.J. Manfredo. Champaign, Illinois: Sagamore Publishing Inc., pp. 77-102.

Roggenbuck, J.W. (1992). Use of Persuasion to reduce resource impacts and visitor conflicts. In Influencing human behavior: Theory and Applications on Recreation, Tourism, and Natural Resources Management, edited by M.J. Manfredo. Champaign, Illinois: Sagamore Publishing Inc., pp. 149-208. 
Roggenbuck, J.W., and J. Passineau (1986). "Use of the field experiment to assess the effectiveness of interpretation." In Proceedings Southeastern recreation research conference, edited by B. McDonald and H.K. Cordell. Recreation Technical Assistance Office, Institute of Community and Area Development, University of Georgia: Athens, GA.

Schultz, P.W., C. Shriver, J.J. Tabanico, and A.M. Khazian (2004). "Implicit connections with nature." Journal of Environmental Psychology, 24, 31-42.

The Lulworth Estate (2002). Management Statement. http://www.lulworth.com/education/

management_statement.htm (accessed February, 2006).

Tilden, F. (1977). Interpreting Our Heritage. Chapel Hill: The University of North Carolina Press.

Thom, V.M. (1980). "Evaluating countryside interpretation: a critical look at the current Situation.” Museums Journal, 79(4): 179-185.

Tubb, K.N. (2003). "An evaluation of the effectiveness of interpretation within Dartmoor National Park in reaching the goals of sustainable tourism development." Journal of Sustainable Tourism, 11(6): 476-498.

UK Fossils Network (2005). Lulworth Cove. http://www.ukfossils.co.uk/Fossils-andGeology/Lulworth-Cove/Introduction-to-Lulworth-Cove.htm (accessed February, 2006).

Widner, C.J., and J. Roggenbuck (2000). "Reducing theft of pertrified wood at Pertrified forest national park." Journal of Interpretation Research, 5(1): 1-18. 
Table 1

Attitude statements associated with local conservation issues

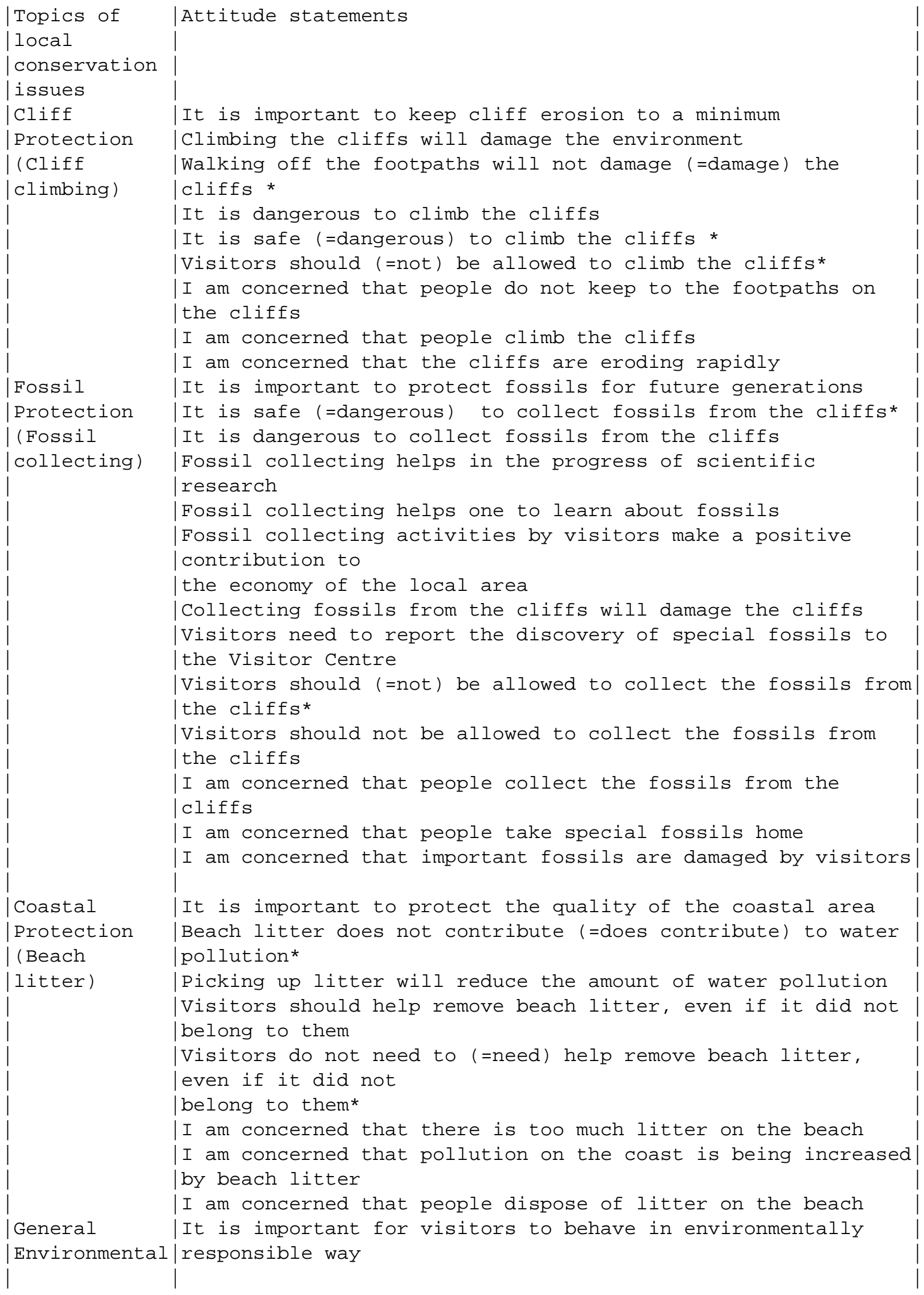


Note: $*$ = seven items of all 31 statements were explained negatively to reduce the response bias.

\section{Table 2}

\section{Behavioral intention statements associated with local conservation issues}

\begin{tabular}{|c|c|}
\hline $\begin{array}{l}\text { Topics of local } \\
\text { conservation issues }\end{array}$ & Behavioral intention statements \\
\hline Cliff Protection & I will keep to the footpaths on the cliffs \\
\hline (Cliff climbing) & I will not climb the cliffs \\
\hline Fossil Protection & I will not collect fossils from the cliffs \\
\hline (Fossil collecting) & $\begin{array}{l}\text { I will inform the Visitor Centre, if I discover } \\
\text { special fossils }\end{array}$ \\
\hline $\begin{array}{l}\text { Coastal Protection } \\
\text { (Beach litter) }\end{array}$ & $\begin{array}{l}\text { I will pick up beach litter when I see it, even if } \\
\text { did not belong to me }\end{array}$ \\
\hline General & I will follow the Code of Conduct (e.g. the \\
\hline Environmental & countryside code, the fossil collecting code, the \\
\hline Behavior & safety code) \\
\hline & $\begin{array}{l}\text { I intend to behave in a way that will not harm plants } \\
\text { and animals }\end{array}$ \\
\hline & I do not intend to disturb any marine life \\
\hline Environmental & I will tell people about the importance of the \\
\hline Activism & geological environment in this area \\
\hline & $\begin{array}{l}\text { I intend to become more involved in environmental } \\
\text { issues }\end{array}$ \\
\hline & $\begin{array}{l}\text { I intend to make a donation to an environmental } \\
\text { organization }\end{array}$ \\
\hline & $\begin{array}{l}\text { I intend to become involved in volunteer work for } \\
\text { environmental conservation activities }\end{array}$ \\
\hline & $\begin{array}{l}\text { I intend to become a member of an environmental } \\
\text { organization }\end{array}$ \\
\hline
\end{tabular}


Table 3

Experiences and plan to visit the Visitor Centre

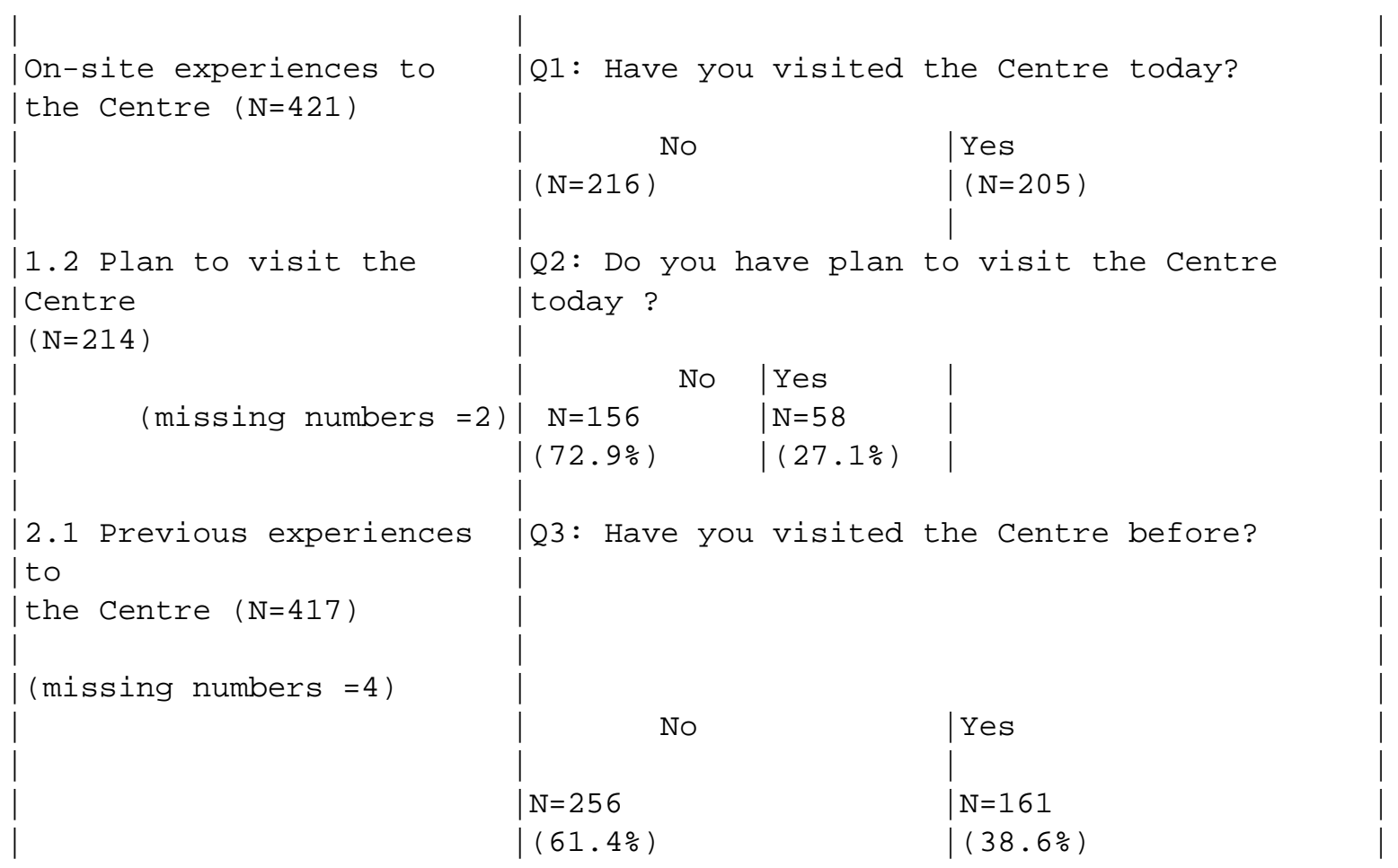


Table 4

Comparison of visitor profile by the three sub-groups

1. Age

$18-25$

$26-35$

$36-45$

$46-55$

$56-65$

Over 66

2.Education

None

High school

qualification

College or

professional

|diploma

University degree

3. Previous

Experiences of

Natural Areas

Less than once to 2

times

per year

| 3 to 4 times per

$\mid$ Percentag

| $\mid$ Non-visi| Intereste

tors |

$(n=122)$

d

visitors

$22.8 \%$

$(n=44)$

$35.0 \%$

$20.3 \%$

$9.1 \%$

$13.0 \%$

$54.5 \%$

$20.5 \%$

$13.6 \%$

$8.1 \%$

12. 3\%

10.8\%

$10 \%$

$7.3 \%$

$6.8 \%$

$11.4 \%$

16

$6.8 \%$

| $26.8 \%$

1

1

$36.4 \%$

$54.5 \%$

$50.0 \%$

Chi-

$23.8 \%$

$22.7 \%$

visitors

$(n=255)$

year

|per year 
Table 5

\section{Comparison of motivation by the three sub-groups}

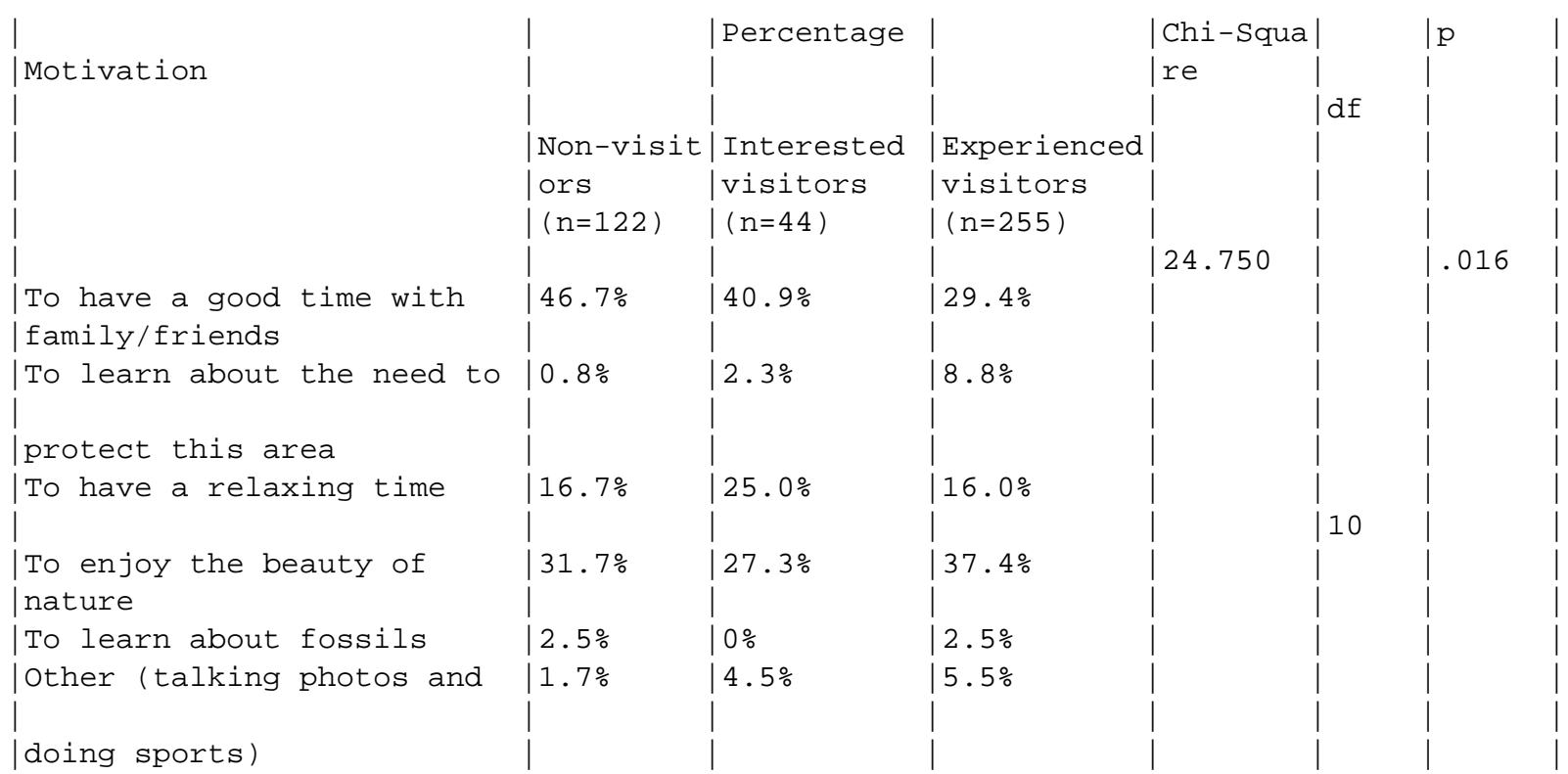

Note: The categories of motivations for visiting the site were modified from the classification developed by Ballantyne et al. (1998). This variable was measured using the nominal scale. 
Table 6

Comparison of the type of interpretation participation by the three sub-groups

\begin{tabular}{|c|c|c|c|c|c|c|}
\hline The type of & & Percentag & & Chi-Squa & & $\mathrm{p}$ \\
\hline interpretive programs & & e & & re & $d f$ & \\
\hline & Non- & Intereste & Experienc & & & \\
\hline & visitors & & & & & \\
\hline & $(\mathrm{n}=122)$ & visitors & visitors & & & \\
\hline & & $(n=44)$ & $(n=255)$ & & & \\
\hline Signboard & $18.0 \%$ & $45.5 \%$ & $40.4 \%$ & 20.910 & 2 & .000 \\
\hline Brochure & $4.1 \%$ & $9.1 \%$ & $14.9 \%$ & 9.924 & 2 & .007 \\
\hline Publications & $1.6 \%$ & $6.8 \%$ & $3.9 \%$ & 2.766 & 2 & .251 \\
\hline Exhibition/displays & $0 \%$ & $0 \%$ & $77.3 \%$ & 241.028 & 2 & .000 \\
\hline Films & $0.8 \%$ & $0 \%$ & $5.9 \%$ & 7.726 & 2 & .021 \\
\hline Computer interactions & $0 \%$ & $0 \%$ & $1.6 \%$ & 2.629 & 2 & .269 \\
\hline Talked to the staff & $0 \%$ & $4.5 \%$ & $3.1 \%$ & 4.500 & 2 & .105 \\
\hline Guided walks & $2.5 \%$ & $0 \%$ & $2.0 \%$ & 1.062 & 2 & .588 \\
\hline Others (e.g. Maps) & $0 \%$ & $2.3 \%$ & $1.2 \%$ & 2.127 & 2 & .345 \\
\hline None & $75.4 \%$ & $47.7 \%$ & $18.8 \%$ & 113.750 & 2 & .000 \\
\hline
\end{tabular}

Note: Percentages may not add up to $100 \%$ due to rounding. 
Table 7

\section{Comparison of attitudes by the three sub-groups}

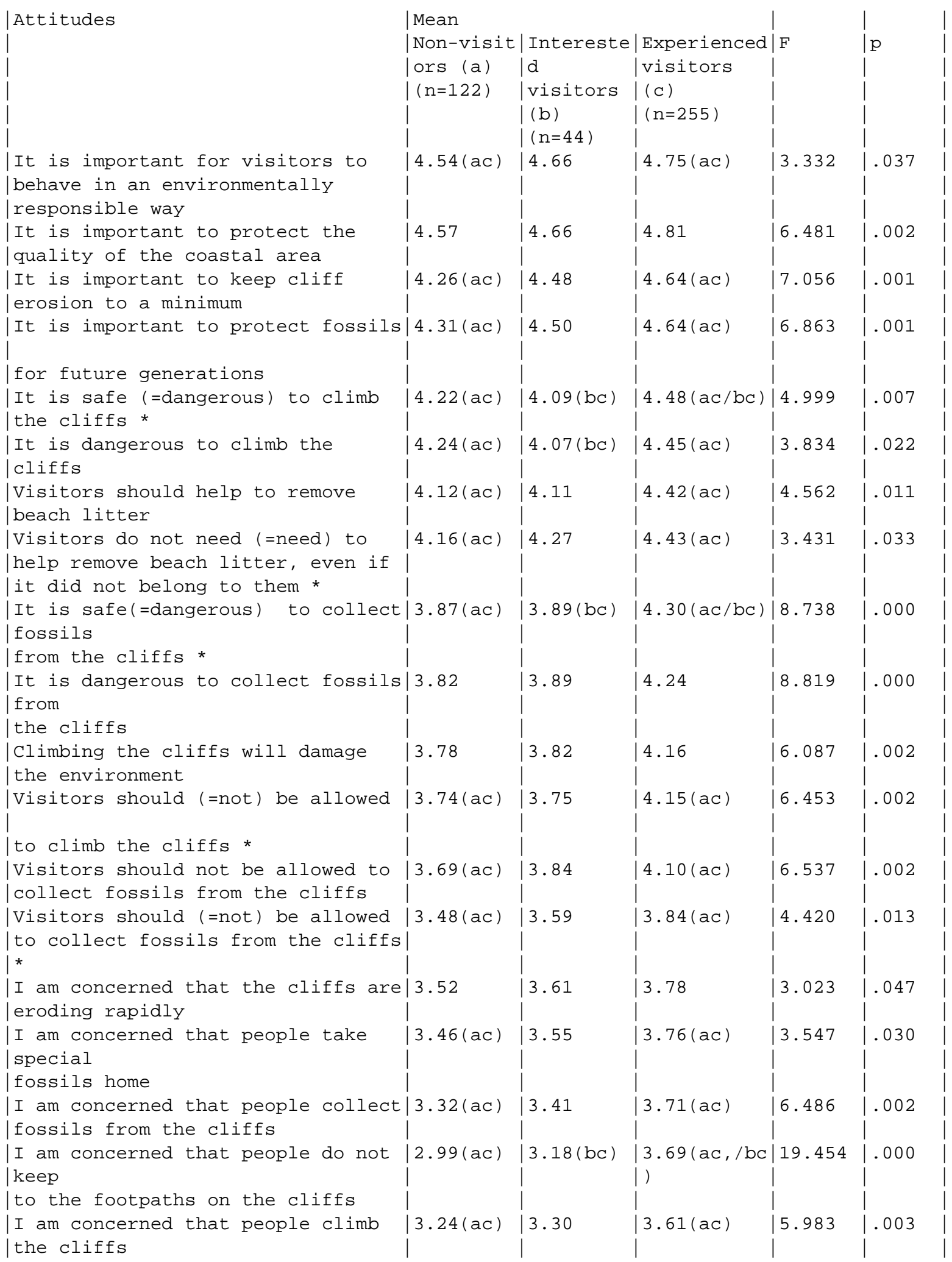

Note: (a) Belief statements (I think that...) using a 5-point scale ( $1=$ strongly disagree to $5=$ strongly agree).

(b) Feelings of concern statements using a 5-point scale ( $1=$ not seriously concerned at all to $5=$ very seriously concerned). * negatively worded items reverse coded prior to the analysis. This table includes only selected 
items with a $p$ value of less than 0.05 . Bolded numbers indicate that significant differences were found between subgroups (subscripts) at $p<.05$ based on post hoc testing. 
Table 8

Comparison of behavioral intentions by the three sub-groups

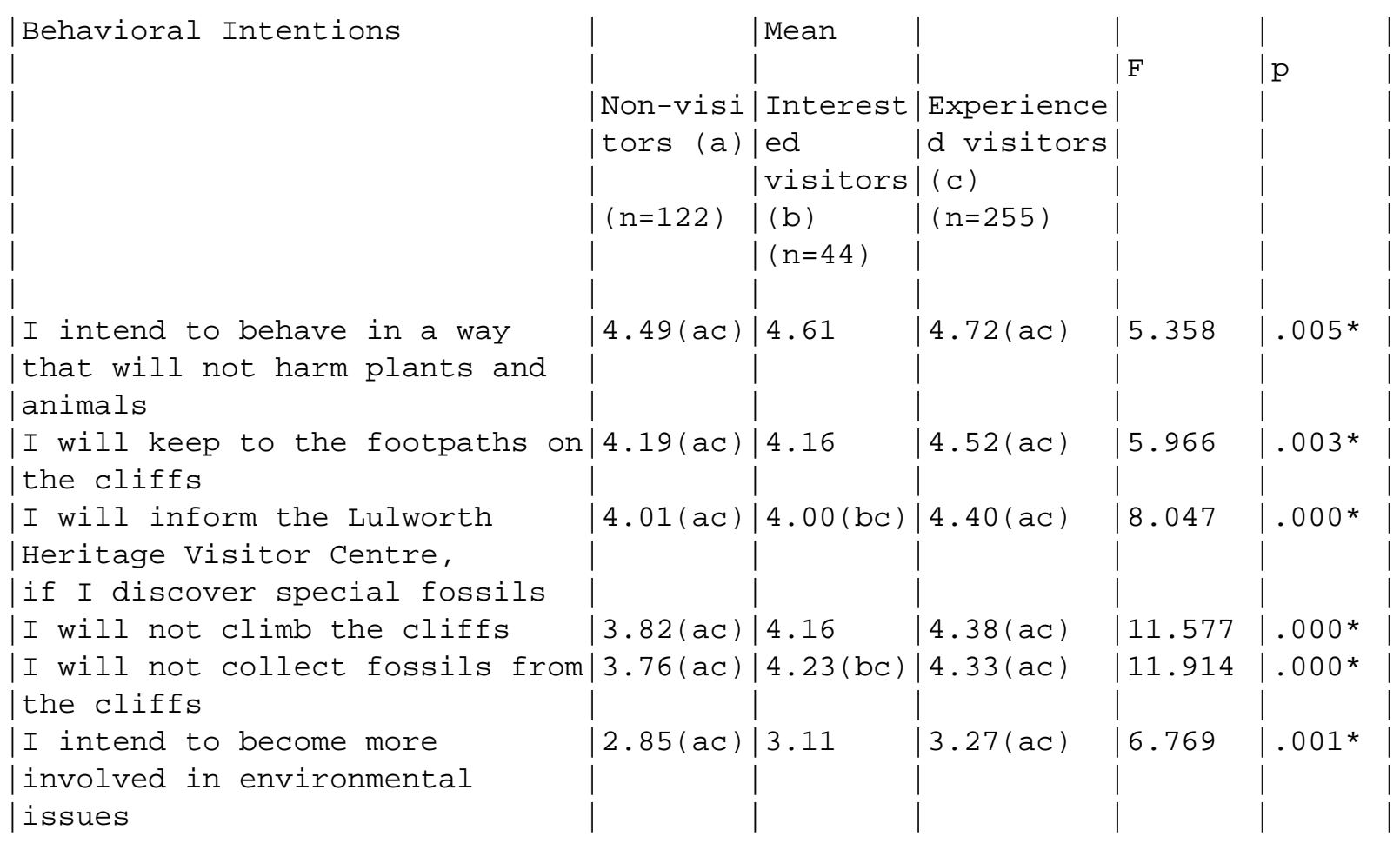

Note: Behavioral intention statements using a 5 -point scale ( $1=$ strongly disagree to $5=$ strongly agree).

$*$ indicates significant difference were found among three subgroups $(p<.05)$. This table includes only selected items with a $p$ value of less than 0.05 . Bolded numbers indicate that significant differences were found between subgroups (subscripts) at $p<.05$ based on post hoc testing. 